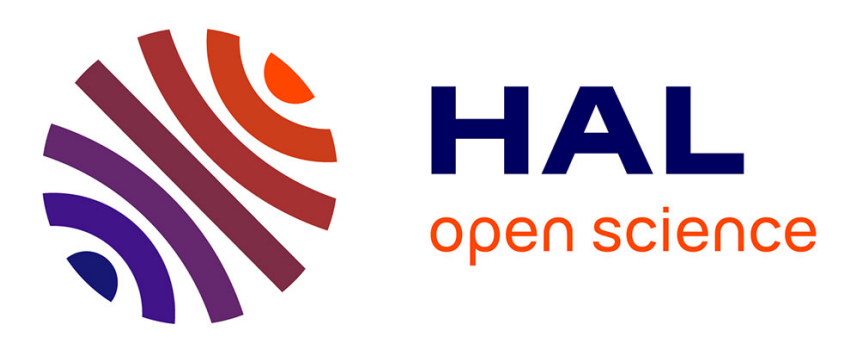

\title{
Three-dimensional scapulothoracic motion following treatment for breast cancer
}

Delva Shamley, Ragavan Srinaganathan, Reza Oskrochi, Ion

Lascurain-Aguirrebeña, Elaine Sugden

\section{- To cite this version:}

Delva Shamley, Ragavan Srinaganathan, Reza Oskrochi, Ion Lascurain-Aguirrebeña, Elaine Sugden. Three-dimensional scapulothoracic motion following treatment for breast cancer. Breast Cancer Research and Treatment, 2008, 118 (2), pp.315-322. 10.1007/s10549-008-0240-x . hal-00478281

\section{HAL Id: hal-00478281 \\ https://hal.science/hal-00478281}

Submitted on 30 Apr 2010

HAL is a multi-disciplinary open access archive for the deposit and dissemination of scientific research documents, whether they are published or not. The documents may come from teaching and research institutions in France or abroad, or from public or private research centers.
L'archive ouverte pluridisciplinaire HAL, est destinée au dépôt et à la diffusion de documents scientifiques de niveau recherche, publiés ou non, émanant des établissements d'enseignement et de recherche français ou étrangers, des laboratoires publics ou privés. 


\title{
Three-dimensional scapulothoracic motion following treatment for breast cancer
}

\author{
Delva Shamley $\cdot$ Ragavan Srinaganathan • \\ Reza Oskrochi · Ion Lascurain-Aguirrebeña • \\ Elaine Sugden
}

Received: 21 July 2008/Accepted: 28 October 2008/Published online: 9 November 2008

(C) Springer Science+Business Media, LLC. 2008

\begin{abstract}
Varying levels of shoulder morbidity following treatment for breast cancer have been reported. Patients report pain, weakness, tightness and reduced functional capacity. Normal painfree motion of the arm and shoulder requires mobility in the scapulothoracic, glenohumeral, acromioclavicular and sternoclavicular joints. Under healthy conditions elevation of the arm is accompanied by scapula retraction, lateral rotation and posterior tilt. However, when scapulothoracic motion is disproportionate to glenohumeral motion, the potential exists for microtrauma and long term pain. A number of studies on women treated for breast cancer have shown limitations in glenohumeral range of movement and a recent report from our laboratory has shown decreased muscle activity in four key muscles acting on the scapula. However, no study has measured the effect of treatment on three-dimensional (3-D) scapulothoracic motion in relation to glenohumeral motion. 152 women treated for unilateral carcinoma of the breast were included in the study. All patients filled out the Shoulder Pain and Disability Index (SPADI). 3-D-kinematic data
\end{abstract}

D. Shamley $(\square)$

Centre for Postgraduate Medical Research and Education, Bournemouth University, Rm 206, Royal London House, Christchurch Rd, Bournemouth BH1 3LT, Dorset, UK

e-mail: dshamley@bournemouth.ac.uk

R. Srinaganathan · I. Lascurain-Aguirrebeña

Department of Physiotherapy, Oxford Brookes University, Oxford, UK

R. Oskrochi

Department of Mathematical Sciences, Oxford Brookes

University, Oxford, UK

E. Sugden

Department of Oncology, Churchill Hospital, Oxford, UK for the humerus and scapula was recorded during scaption on the affected and unaffected side. The association between kinematic data, SPADI and covariates was determined using random effects multiple regression techniques. All scapula kinematic parameters were significantly altered on the side of the carcinoma in breast cancer survivors. Both reported levels of pain and dysfunction were associated with altered kinematics. High levels of pain and disability were reported for up to 6 years post surgery. Patients with the left side affected reported higher levels of pain and demonstrated more significant scapulathoracic dysfunction independent of dominance. Altered movement patterns were different for left versus right side affected. Left side affected patients need to be considered as a group of patients at risk of experiencing higher levels of pain and showing greater shoulder dysfunction. Whether cause or effect, pain reports are accompanied by 3-dimensional scapula dysfunction which mimics that of many other shoulder conditions.

Keywords Kinematics - Shoulder - Pain lateralisation

\section{Introduction}

The potential for shoulder morbidity following treatment for breast cancer is an established fact [1-6]. Risk factors for acute postoperative pain include anxiety [7] and for chronic postoperative pain more invasive surgery, radiotherapy and acute post-operative pain [8, 9]. Patient reports of arm morbidity include pain, weakness, tightness and reduced functional capacity $[8,9]$.

Normal painfree motion of the arm and shoulder requires mobility in the scapulothoracic, glenohumeral, acromioclavicular and sternoclavicular joint [10]. The 
shoulder mechanism involves a combination of rotations and translations [11] about these four regions resulting in 3-dimensional (3-D) movement. However, recordings of 3dimensional scapulothoracic motion are traditionally difficult to obtain due to the movement of the scapula and the clavicle beneath the skin. An electromagnetic motion tracking system (Polhemus Fastrak ${ }^{\mathrm{TM}}$ ) has been shown to be a valid, non-invasive technique for measuring 3-D motion of the scapula [12]. This system uses local coordinates set up with respect to the patients' body and expresses rotations of the scapula as Euler angles. The International Shoulder Group (ISB) protocol, adopted for standardising reporting of shoulder complex motion, uses a set sequence of rotations to allow for comparisons of results across studies [11]. This protocol describes a sequence of axes $\left(\mathrm{Y}, \mathrm{X}^{\prime}, \mathrm{Z}^{\prime \prime}\right)$ about which the scapula rotates to describe lateral/medial rotation, anterior/posterior tilt and protraction/retraction during elevation of the arm. Under healthy conditions elevation of the arm is accompanied by scapula retraction, lateral rotation and posterior tilt [13-16].

However, when scapulothoracic motion is disproportionate to glenohumeral motion, the potential exists for microtrauma and long term pain [17]. A number of studies on women treated for breast cancer have shown limitations in glenohumeral range of movement $[2,6,18,19]$ and a recent report from our laboratory [20] has shown decreased muscle activity in four key muscles controlling scapula movement [serratus anterior (SA), upper trapezius (UT), pectoralis major (PM) and rhomboid (Rhom)]. The most notable reduction in activity was seen in UT and Rhom, both of which were associated with a high Shoulder Pain and Disability Index (SPADI). Furthermore we found both $\mathrm{PM}$ and PMinor to be reduced in size on the side of the cancer. These findings suggest alterations to the normal biomechanics of the shoulder complex. However, no study has measured the effect of treatment for breast cancer on 3-D scapulothoracic motion in relation to glenohumeral motion.

Table 1 Inclusion and exclusion criteria

\footnotetext{
${ }^{\text {a }}$ Mastectomy included modified radical mastectomy, radiotherapy $=$ radiotherapy to the chest
}

a Mastectomy included
modified radical mastectomy,
radiotherapy = radiotherapy to
the chest

The primary aim of this study was to describe any differences in scapulothoracic kinematics between the affected and unaffected sides. Secondary aims were to evaluate associations between these data and the following covariates: degree of humeral elevation and direction of movement (up/down), age, time since surgery, medical treatment protocol, SPADI, chemotherapy, handedness, and whether left or right side was affected.

\section{Method}

This was a cross sectional study of patients treated for unilateral carcinoma of the breast. Ethical clearance was granted by the Oxfordshire Local Research Ethics Committee (A02, 064).

\section{Participants}

A power calculation for studies with correlated observations was employed to calculate the required number of patients to detect a difference of $4^{\circ}$ [21] of scapula rotation for 24 observations per patient. A sample size of 131 patients each with 24 repeated observations ( $80 \%$ power; $\alpha=0.05$, standard deviation of 9.98 , and with interclass correlation of 0.85 ) was found to have sufficient power. 152 women meeting the inclusion and exclusion criteria (Table 1) consented to take part in the study. The time since surgery ranged from 6 months to 6 years.

\section{Instrumentation}

\section{The Polhemus Fastrak ${ }^{T M}$}

Glenohumeral elevation in degrees was measured using an electromagnetic position and orientation movement tracking system. This comprises a three axis magnetic dipole source (or transmitter) and a three axis magnetic sensor (or receiver), together with related electronic equipment. The

\begin{tabular}{ll}
\hline Inclusion criteria & Exclusion criteria \\
\hline $\begin{array}{l}\text { Unilateral carcinoma of the breast } \\
\text { Treatment protocols }\end{array}$ & Reconstructive surgery \\
$\begin{array}{l}\text { (1) Mastectomy } \\
\text { (2) Mastectomy + radiotherapy }\end{array}$ & $\begin{array}{c}\text { Current or previous history of shoulder } \\
\text { complex trauma, surgery, pathology } \\
\text { or dysfunction of the contra-lateral arm }\end{array}$ \\
(3) Mastectomy + radiotherapy + axillary radiotherapy & $\begin{array}{l}\text { Lumpectomy } \\
\text { (4) Wide local excision }+ \text { radiotherapy }\end{array}$ \\
$\begin{array}{l}\text { (5) Wide local excision }+ \text { axillary } \\
\text { radiotherapy }+ \text { radiotherapy }\end{array}$ & Current or previous history of cervical \\
(6) Wide local excision + axillary & \\
clearance + radiotherapy & \\
\hline
\end{tabular}


sensors are small and lightweight and were attached to the skin as described previously with the exception of the thoracic sensor which was placed on T1 in our study [13]. Scapula and humeral surface mounted sensors have a rootmean-square (RMS) error of less than $5^{\circ}$ when compared to sensors attached to bone pins [12,13]. Within a $76 \mathrm{~cm}$ source- to- sensor separation, the RMS system accuracy is $0.15^{\circ}$ for orientation and $0.3-0.8 \mathrm{~mm}$ for position [21]. The transmitter generates a low frequency magnetic field composed of three sequential excitation states, each of which produces an independent excitation vector.

The transmitter was attached to an upright plastic pole and used as the global reference frame. Patients were asked to stand within the frame and their bony landmarks digitised in order for the Polhemus Fastrak system to produce anatomical axes [15].

\section{Shoulder pain and disability index}

All patients filled in a SPADI questionnaire immediately prior to kinematic data being collected. The SPADI is a valid measure of pain and disability for shoulder dysfunction with high levels of sensitivity and reliability [22, 23]. The scale is a visual analogue scale with 13 items (5 for pain and 8 for disability). Total scores for pain range from a minimum of $0 \mathrm{~mm}$ to a maximum of $500 \mathrm{~mm}$ and for disability $0-800 \mathrm{~mm}$. Zero representing no symptoms of pain or disability.

\section{Arm elevation trials}

Once the digitisation protocol was complete patients were asked to elevate their arm in the plane of the scapula, taken as $40^{\circ}$ anterior to the coronal plane (scaption). With the patient standing, both arms were taken through three repeat movements of scaption, each one matched to a metronome at one complete cycle every $8 \mathrm{~s}$ ( $4 \mathrm{~s}$ to raise the arm and $4 \mathrm{~s}$ to lower the arm) and guided to remain in this plane by a flat surface oriented $40^{\circ}$ anterior to the coronal plane. The patient was encouraged to elevate their arm as high as they could in a natural, relaxed manner and given three practise movements. This process was repeated on both sides and the side recorded first was randomly selected.

\section{Reliability}

Fastrak data collection was carried out by the same two observers (one applied sensors to patient and gave instructions, one operated the computer) blind to the SPADI data. Intrarater reliability was assessed by carrying out repeat measures on a different day for all movements for a random sample of five participants.
Data reduction and analysis

Descriptive analyses were conducted to assess demographic and clinical characteristics of the sample.

Scapula rotation and humeral elevation data from the three repeat scaption movements were averaged at every $10^{\circ}$ interval of humeral elevation for subsequent analyses. The Motion Monitor ${ }^{\mathrm{TM}}$ software system used in this study determines the orientation of the scapula relative to the trunk using the ISB protocol [11]. Angular rotations of the scapula were plotted as dependent variables against humeral elevation as the independent variable.

As these are paired observations for each individual, scapula measurement value of the unaffected arm was subtracted from scapula measurement value of affected arm for the scapulae of the same patients, at the same elevation point. Since strong associations between changes in measurements of the same scapula at two different elevation points (repeated measures) was observed, statistical analyses that accounted for these complex associations between observations were conducted.

\section{Statistical analyses}

Statistical analysis of Fastrak data utilised a linear mixed (random effect) model in order to account for the within class associations and to control for correlated observations [24].

Fastrak scapulothoracic measures for affected minus unaffected sides were the dependent variable and the following independent variables were included in the analysis: degree of humeral elevation and direction of movement (up/down), age, time since surgery, medical treatment protocol, SPADI (pain and disability), chemotherapy, handedness, and whether left or right side was affected. The corresponding values of the other two scapulothoracic measures were also included as independent variables in order to control for within scapula correlation. The correlations between repeated observations for each patient were controlled by introducing a patient specific random effect into the regression model. This regression can identify the subset of covariates which are significantly associated $(P \leq 0.05)$ with a change in scapula measurement (i.e. change between affected and unaffected arm). The true magnitude of the difference between affected and unaffected sides, while controlling for the effects of all other prognostic factors, is reflected in the full linear mixed regression model analysis with all possible prognostic factors included.

Mean values for repeat measures of all scapulothoracic movements were used to determine intra-rater reliability for Fastrak measures using the Bland-Altman test [25]. 


\section{$S P A D I$}

A separate one-way ANOVA was conducted to compare the individual items on the pain and disability indices for each of the time scales since surgery $(0-2,2-4,4-6$ years).

\section{Results}

Demographic and clinical details are shown in Table 2. The number of patients with left and right sides affected were closely represented. Intra-rater reliability for Fastrak procedures was 0.98 .

Table 2 Demographic and clinical data for study sample $(n=152)$

\begin{tabular}{|c|c|}
\hline & $\begin{array}{l}\text { Descriptive } \\
\text { values }\end{array}$ \\
\hline Number of patients & 152 \\
\hline Duration since surgery-mean days (SD) & $1144(537)$ \\
\hline Age-mean years $(\mathrm{SD})$ & $61.86(8.99)$ \\
\hline \multicolumn{2}{|l|}{ Affected side } \\
\hline Left & $48.4 \%$ \\
\hline Right & $51.6 \%$ \\
\hline \multicolumn{2}{|l|}{ Handedness } \\
\hline Left & $8.6 \%$ \\
\hline Right & $91.4 \%$ \\
\hline \multicolumn{2}{|l|}{ Dominant side affected } \\
\hline Left & $8 \%$ \\
\hline Right & $92 \%$ \\
\hline \multicolumn{2}{|l|}{ Chemotherapy } \\
\hline Yes & $16.6 \%$ \\
\hline no & $83.4 \%$ \\
\hline Mastectomy & $13.6 \%$ \\
\hline Mastectomy + radiotherapy & $7.2 \%$ \\
\hline $\begin{array}{l}\text { Mastectomy }+ \text { radiotherapy }+ \text { axillary } \\
\text { radiotherapy }\end{array}$ & $9.2 \%$ \\
\hline Wide local excision + radiotherapy & $38.6 \%$ \\
\hline $\begin{array}{l}\text { Wide local excision }+ \text { axillary } \\
\text { radiotherapy }+ \text { radiotherapy }\end{array}$ & $18.3 \%$ \\
\hline $\begin{array}{l}\text { Wide local excision }+ \text { axillary } \\
\text { clearance }+ \text { radiotherapy }\end{array}$ & $13.1 \%$ \\
\hline Total SPADI score-mean (SD) & $166.24(185.99)$ \\
\hline
\end{tabular}

SPADI data

Total SPADI scores as a function of time since surgery are shown in Table 3. No significant difference between years was shown but both pain and disability scores are higher at the 4-6 year interval.

Analysis of pain and disability as a function of side affected revealed significantly higher levels of pain reported by patients with left side affected (Table 4).

This was further broken down to determine which of the three sub-categories of pain intensity was most likely to be contributing to this result (Table 5). The greatest percentage of patients reporting pain over $50 \mathrm{~mm}$ were left side affected while the greatest percentage of patients reporting pain less than $30 \mathrm{~mm}$ were right side affected. Patients with the left side affected show a slightly higher percentage of more aggressive treatment protocols (Table 6).

\section{Kinematic data}

Figures 1, 2, and 3 represent the patterns of scapulothoracic movement during elevation and depression of the arm. For within subject comparisons the right affected graph should be compared with the left unaffected graph

Table 4 Difference between mean pain and disability scores for side affected

\begin{tabular}{llllll}
\hline & Side affected & Mean & SD & SEM & $P$ value \\
\hline SPADI pain (mm) & Left & 82.90 & 89.72 & 2.04 & 0.000 \\
& Right & 70.49 & 90.15 & 2.08 & \\
SPADI disability (mm) & Left & 81.59 & 86.01 & 1.96 & 0.45 \\
& Right & 80.23 & 100.28 & 2.31 & \\
\hline
\end{tabular}

Table 5 Sub-categories of mean pain scores as a function of side affected

\begin{tabular}{lll}
\hline Pain $(\mathrm{mm})$ & Left side affected $(\%)$ & Right side affected $(\%)$ \\
\hline $0-30$ & 42.7 & 57.3 \\
$30-50$ & 24.7 & 75.3 \\
$>50$ & 56.8 & 43.2 \\
\hline
\end{tabular}

Table 3 Total pain and disability scores as a function of time intervals

\begin{tabular}{|c|c|c|c|c|c|c|}
\hline Groups & $N$ & $\operatorname{Minimum}(\mathrm{mm})$ & Maximum (mm) & Mean (mm) & $\mathrm{SD}(\mathrm{mm})$ & Between group $P$-value \\
\hline Pain $0-2$ years & 39 & 0.00 & 256.00 & 73.59 & 75.63 & 0.324 \\
\hline Pain 2-4 years & 65 & 0.00 & 365.00 & 71.26 & 89.44 & \\
\hline Pain 4-6 years & 49 & 0.00 & 364.00 & 96.49 & 110.48 & \\
\hline Dysfunction 0-2 years & 39 & 0.00 & 369.00 & 68.62 & 79.91 & 0.289 \\
\hline Dysfunction 2-4 years & 65 & 0.00 & 417.00 & 83.46 & 100.91 & \\
\hline Dysfunction 4-6 years & 49 & 0.00 & 367.00 & 101.96 & 110.24 & \\
\hline
\end{tabular}


Table 6 Distribution of treatment variables for side affected

\begin{tabular}{llc}
\hline & $\begin{array}{l}\text { Percentage of left } \\
\text { side affected }\end{array}$ & $\begin{array}{l}\text { Percentage of right } \\
\text { side affected }\end{array}$ \\
\hline Mastectomy & 15 & 13 \\
Mastectomy + radiotherapy & 10 & 5 \\
Mastectomy + chest radiotherapy + axillary radiotherapy & 7 & 11 \\
WLE + chest radiotherapy & 35 & 42 \\
WLE + chest radiotherapy + axillary clearance & 16 & 20 \\
WLE + axillary radiotherapy + chest radiotherapy & 17 & 9 \\
Received chemotherapy & 19 & 15 \\
\hline
\end{tabular}

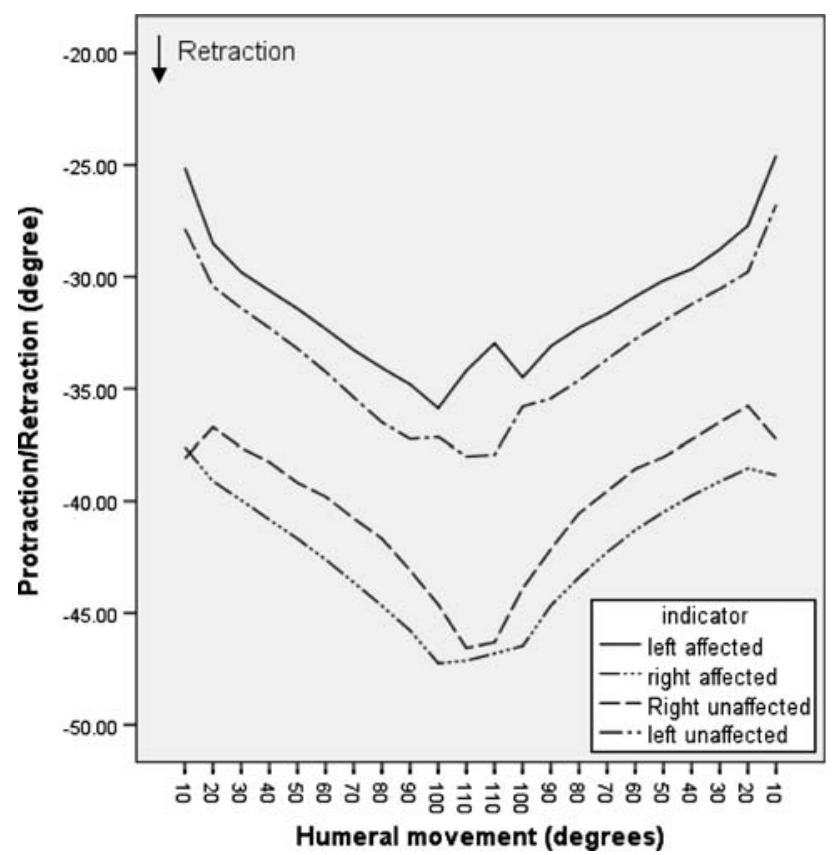

Fig. 1 Mean scapula protraction/retraction plotted against humeral elevation and depression for affected and unaffected sides $(n=152)$. Arrow represents direction of retraction. Difference between affected and unaffected arm is significant $(P=0.034)$

and visa versa. The pattern of movement for scapula protraction/retraction and rotation shows opposite effects when the right side is affected (Figs. 1, 3). Without controlling for the effects of other prognostic factors only the difference between anterior/posterior tilt of the affected and unaffected sides is not significant. Once prognostic factors are considered this becomes a significant difference (Tables 7, 8, and 9). Thus the averages shown in these figures do not accurately reflect the actual observed variation in shoulder movement between subjects because the effects of the prognostic factors have not been controlled.

The effects of other prognostic factors, is better reflected in the regression analysis for longitudinal outcomes with all possible prognostic factors included.

All scapulothoracic movements were significantly altered on the affected side compared to the unaffected side

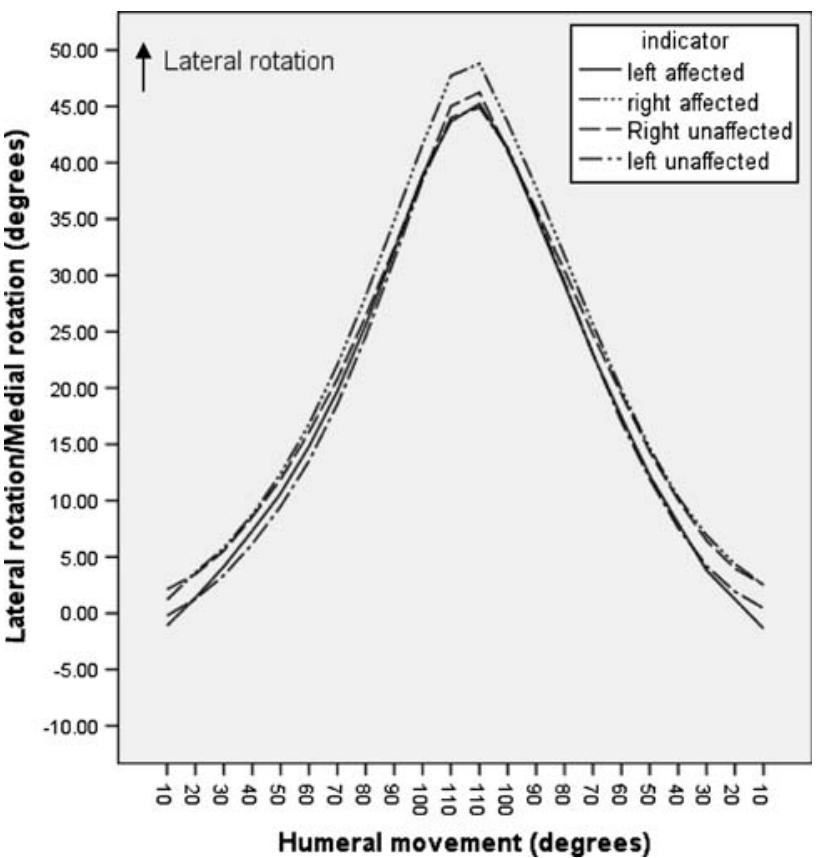

Fig. 2 Mean scapula lateral/medial rotation plotted against humeral elevation and depression for affected and unaffected sides $(n=152)$. Arrow represents direction of lateral rotation. Difference between affected and unaffected arm is significant $(P=0.000)$

and were independent of the type of medical management. The difference was significantly larger when the left side was affected (Tables 7, 8, and 9). No effect for hand dominance was found and an exploration of radiotherapy delivery did not reveal any general protocol differences for the left side. Left scapulothoracic dysfunction included increased protraction, increased posterior tilt and decreased lateral rotation, all of which were significantly associated with having had chemotherapy (Tables 7, 8, and 9). Right scapulothoracic dysfunction included increased retraction, increased posterior tilt and increased lateral rotation. Only scapulothoracic lateral rotation differences were associated with the downward movement (Table 9).

Both pain and disability were significantly associated with scapulothoracic dysfunction (Tables 7, 8, and 9). 


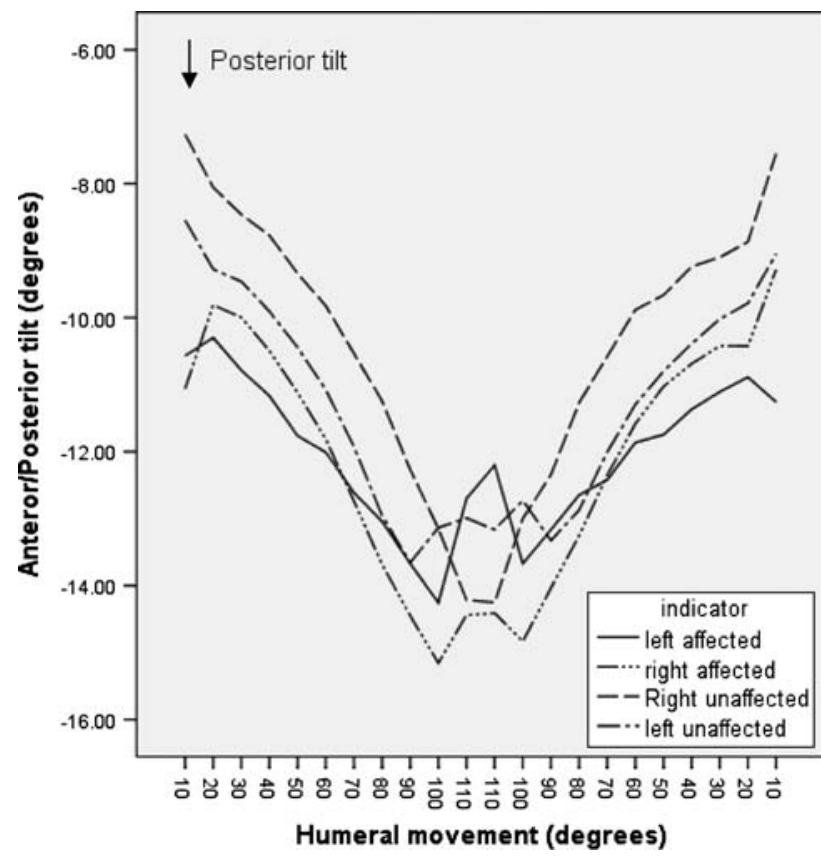

Fig. 3 Mean scapula anterior/posterior tilt plotted against humeral elevation and depression for affected and unaffected sides $(n=152)$. Arrow represents direction of posterior tilt. Difference between affected and unaffected arm is not significant $(P=0.518)$

Table 7 Random effects multiple regression for associations between scapula protraction/retraction and covariates

\begin{tabular}{lrrrr}
\hline Protraction/retraction & Coef. & Sig & (95\% Conf. interval) \\
\hline Left side affected & 20.38 & 0.001 & 8.45 & 32.30 \\
Pain score & -0.13 & 0.035 & -0.25 & -0.00 \\
Received chemotherapy & 19.19 & 0.022 & 2.81 & 35.56 \\
Lateral/medial rotation & 0.21 & 0.000 & 0.16 & 0.26 \\
Anterior/posterior tilt & 0.65 & 0.000 & 0.60 & 0.69 \\
Constant & 25.29 & 0.305 & -23.08 & 73.68 \\
\hline
\end{tabular}

Dependent variable: scap protraction/retraction affected-unaffected, reference category for treatment was WLE + Radiotherapy. Only significant variables are shown

Table 8 Random effects multiple regression for associations between scapula anterior tilt/posterior tilt and covariates

\begin{tabular}{lrlrr}
\hline Anterior/posterior tilt & \multicolumn{1}{c}{ Coef. } & Sig & \multicolumn{2}{c}{ (95\% Conf. interval) } \\
\hline Left side affected & -15.38 & 0.001 & -24.67 & -6.08 \\
Pain score & 0.11 & 0.017 & 0.02 & 0.21 \\
Disability score & -0.10 & 0.022 & -0.20 & -0.01 \\
Received chemotherapy & -14.52 & 0.026 & -27.27 & -1.77 \\
Protraction/retraction & 0.67 & 0.000 & 0.65 & 0.70 \\
Lateral/medial rotation & -0.18 & 0.000 & -0.21 & -0.16 \\
Constant & -20.95 & 0.27 & -58.61 & 16.71 \\
\hline
\end{tabular}

Dependent variable: scap anterior tilt/posterior tilt affected-unaffected, reference category for treatment was WLE + Radiotherapy. Only significant variables are shown
Table 9 Random effects multiple regression for associations between scapula lateral rotation/medial rotation and covariates

\begin{tabular}{lrlrr}
\hline Lateral/medial rotation & \multicolumn{1}{c}{ Coef. } & Sig & \multicolumn{2}{c}{ (95\% Conf. interval) } \\
\hline Downward movement & -0.45 & 0.00 & -0.74 & -0.15 \\
Higher degree of elevation & 0.20 & 0.00 & 0.15 & 0.24 \\
Left side affected & -8.58 & 0.00 & -13.15 & -4.02 \\
Pain score & 0.05 & 0.02 & 0.00 & 0.10 \\
Disability score & -0.05 & 0.02 & -0.09 & -0.00 \\
Received chemotherapy & -7.82 & 0.01 & -14.02 & -1.61 \\
Pro/retraction & 0.23 & 0.00 & 0.18 & 0.27 \\
Anterior/posterior tilt & -0.20 & 0.00 & -0.25 & -0.16 \\
Constant & -12.44 & 0.18 & -30.65 & 5.76 \\
\hline
\end{tabular}

Dependent variable: scap lateral rotation/medial rotation affectedunaffected, reference category for treatment was WLE + Radiotherapy. Only significant variables are shown

\section{Discussion}

This study has shown altered movement patterns in the shoulders of patients treated for breast cancer. Irrespective of the side affected, patients in this study reported pain levels sufficient to interfere with ADL [26-28] for up to 6 years after surgery.

The most significant finding is the presence of higher levels of reported pain in patients with the left side affected. This evidence of pain lateralisation was unrelated to handedness which supports findings under different conditions [29, 30]. A number of studies have reported increased frequency of pain on the left side with higher intensity and lower tolerance threshold than on the right $[31,32]$. Furthermore, a functional asymmetry towards the right hemisphere for pain perception has been reported by several authors [29, 32]. The right hemisphere is also dominant in processing emotional experience [33], suggesting a possible link between the right hemisphere and the emotional component of pain processing. This is supported by evidence that factors such as anxiety and anticipation of pain have been shown to stimulate affective/ cognitive pain perception pathways [34-36]. Indeed anxiety is a risk factor for pain in breast cancer [7] and a recent review has demonstrated effective management of pain in breast cancer patients with the use of CBT [37]. In the absence of any general difference in medical protocol, assigning high intensity left sided pain to a more affective/ cognitive origin is tempting.

However, pain perception is not that simple and is known to be a subjective experience dependent upon emotional, chemical and physical factors [38]. Radiotherapy and chemotherapy both have the potential to induce cell damage and promote chemical nociceptor stimulus via pro-inflammatory cytokines [39, 40]. Additionally, physical changes in muscle and joint movement have been 
shown in our studies [20]. Since decreased pain threshold on the left has consistently been shown to apply to deep pressure stimuli such as that transmitted by muscle nociceptors [29, 41], it is possible that high levels of pain in left side affected patients is due to muscle nociceptor stimulation. Right side affected patients may overcome some pain and dysfunction due to the need to use the dominant arm. This use of the arm may also account for the observed increased retraction of the scapula which would assist with raising the arm. If this is the case it is possible that a protective, limited movement dysfunction is leading to higher levels of perceived pain on the left. This area needs further research in order to fully understand why some women develop increased pain and what makes left side affected patients at risk of developing higher levels of pain and dysfunction.

Altered movement shown in our studies could be the physical manifestation of either pain pathway or may themselves induce pain. UT and SA work as a force couple to protract elevate and laterally rotate the scapula thereby ensuring clearance of the subacromial arch [10]. The loss of UT and SA activity previously shown would alter the force couple produced by these muscles, decreasing upward rotation of the scapula $[14,42]$. Decreased upward rotation has been implicated in impingement syndrome [43, 44] and glenohumeral instability [45, 46]. Although impingement is generally associated with anterior scapula tilt, the possibility of different sites of impingement has been raised [43] and may be associated with different angles of tilt. Analysis of all scapula movements has shown that lateral rotation is the most important kinematic parameter associated with dysfunction in shoulder disorders [47]. The increased posterior tilt seen in this study might therefore be a compensatory movement to increase the subacromial space due to the loss of lateral rotation. This loss of lateral rotation was enhanced on the downward or eccentric movement of the arm suggesting poor muscle control of the scapula. Breast cancer patients are clearly demonstrating movement dysfunction which mimics that found in common shoulder conditions. Our laboratory is currently looking at concomitant muscle control of scapula kinematic parameters.

\section{Conclusion}

Patients treated for breast cancer have shown significant pain and movement dysfunction at the shoulder complex. Those patients with the left side carcinoma should be recognised as a group most likely to develop higher levels of pain and dysfunction after treatment. The most important clinical implication is that until we know more about the mechanisms causing pain and dysfunction, any package of care should consider a cognitive behavioural approach and include strategies for region specific rehabilitation as well as general health and well being of the breast cancer survivor.

Acknowledgments We would like to thank the Oxford Hospitals Research Charities for providing the funds for this research. Thank you to Professor Raymond Lee and Dr Karen Robb and for their critical reviews.

\section{References}

1. Box RC, Reul-Hirche H, Bullock-Saxton JE, Furnival C (2002) Shoulder movement after breast cancer surgery: results of a randomised controlled study of postoperative physiotherapy. Breast Cancer Res Treat 75(1):35-45

2. Rietman J, Dijkstra P, Hoekstra H, Eisman W, Szabo B, Groothoff J, Geertzen J (2003) Late morbidity after treatment of breast cancer in relation to daily activities and quality of life: a systematic review. Eur J Surg Oncol 29:229-238. doi:10.1053/ ejso.2002.1403

3. Gossenlink R, Rouffaer L, Vanhelden P, Piot W et al (2003) Recovery of upper limb function after axillary dissection. J Surg Oncol 83:204-211. doi:10.1002/jso.10271

4. Gutman H, Kersz T, Barzilai T et al (1990) Achievements of physical therapy in patients after modified radical mastectomy compared with quadrantechtomy, axillary dissection and radiation for carcinoma of the breast. Arch Surg 125:389-391

5. Gerber L, Lampert M, Wool C et al (1992) Comparison of pain, motion and oedema after modified radical mastectomy versus local excision with axillary dissection and radiation. Breast Cancer Res Treat 21:139-145. doi:10.1007/BF01836960

6. Keramopoulos A, Tsionou C, Minaretzis D et al (1993) Arm morbidity following treatment for breast cancer of total axillary dissection: a multivariated approach. Oncology 50:445-449

7. Katz J, Poleshuck EL, Katz J, Andrus CH, Hogan LA, Jung BF, Kulick DI, Dworkin RH (2005) Risk factors for acute postoperative pain and its persistence following breast cancer surgery: a prospective study. Pain 119:16-25. doi:10.1016/j.pain.2005.09.008

8. Karki A, Simonen R, Malkia E, Selfe J (2005) Impairments, activity limitations and participation restrictions 6 and 12 months after breast cancer operation. J Rehabil Med 37:180-188

9. Isaksson G, Feuk B (2000) Morbidity from axillary treatment in breast cancer. A follow up study in a district hospital. Acta Oncol 39:335-336. doi:10.1080/028418600750013104

10. Donatelli RA (2000) Physical therapy of the shoulder, 3rd edn. Churchill Livingstone Inc, London

11. Wu G, Van Der Helm FC, Veeger HE et al (2005) ISB recommendations on definitions of joint coordinate systems of various joints for the reporting of human joint motion-part II: shoulder, elbow, wrist and hand. J Biomech 38:981-992. doi:10.1016/j. jbiomech.2004.05.042

12. Karduna AR, McClure PW, Michener LA, Sennett B (2001) Dynamic measurements of three-dimensional scapular kinematics: a validation study. J Biomech Eng 123(2):184-190. doi: $10.1115 / 1.1351892$

13. Dayanidhi S, Orlin M, Kozin S, Duff S, Karduna A (2005) Scapular kinematics during humeral elevation in adults and children. Clin Biomech (Bristol, Avon) 20:600-606. doi:10.1016/ j.clinbiomech.2005.03.002

14. Ludewig PM, Cook TM, Nawocszenski DA (1996) Threedimensional scapula orientation and muscle activity at selected positions of humeral elevation. JOSPT 24(2):57-65 
15. Van der Helm F, Pronk G (1995) Three-dimensional recording and description of motions of the shoulder mechanism. J Biomech Eng 117:27-40. doi:10.1115/1.2792267

16. Ebaugh DD, McLure PW, Karduna AR (2005) Three-dimensional scapulothoracic motion during active and passive arm elevation. Clin Biomech (Bristol, Avon) 20:700-709. doi: 10.1016/j.clinbiomech.2005.03.008

17. McQuade KJ, Wei SH, Smidt GL (1995) Effects of local muscle fatigue on three-dimensional scapulo-humeral rhythm. Clin Biomech (Bristol, Avon) 10:144-148. doi:10.1016/0268-0033 (95) $93704-W$

18. Sneeu KCA, Arenson NK, Jaarnold JR (1992) Cosmesis and functional outcomes of breast conserving treatments for early stage breast cancer. Comparisons of patients ratings, observers ratings and objective measurements: a multivariate approach. Oncology 50:445-449

19. Kuehn T, Klauss W, Darsow M, Regele S, Flock F, Maiterth C et al (2000) Long term morbidity following axillary dissection in breast cancer patients-clinical assessment, significance for life quality and the impact of demographic, oncologic and therapeutic factors. Brest Cancer Res Treat 64:275-286. doi:10.1023/A: 1026564723698

20. Shamley DR, Srinaganathan R, Weatherall R, Oskrochi R et al (2007) Changes in muscle size and activity following treatment for breast cancer. Breast Cancer Res Treat 106(1):19-27

21. Lukasiewicz AM, McClure P, Michener L et al (1999) Comparison of 3-Dimensional scapular positions and orientation between subjects with and without shoulder impingement. J Ortho Sports Phys Ther 29(10):574-586

22. Roach KE, Budiman-Mak E, Songsriridej N, Lertatanakul Y (1991) Development of a shoulder pain and disability index. Arthritis Care Res 4:143-149. doi:10.1002/art.1790040403

23. Williams JW, Holleman DR, Simel DL (1995) Measuring shoulder function with the shoulder pain and disability index. J Rheumatol 22(4):727-732

24. Oskrochi G and Shamley D (2007) Muscle activity changes at the shoulder after treatment for breast cancer; a multivariate random effects modeling approach. Abstract, 28 annual conference of ISCB: 202

25. Bland JM, Altman DG (1986) Statistical methods for assessing agreement between two methods of clinical measurement. Lancet 1:307-310

26. Robb KA, Newham DJ, Williams JE (2007) Transcutaneous electrical nerve stimulation vs. transcutaneous spinal electroanalgesia for chronic pain associated with breast cancer treatments. J Pain Symptom Manag 33(4):410-419

27. Twycross R, Harcourt J, Bergl S (2006) A survey of pain in patients with advanced cancer. J Pain Symptom Manag 12(5):273-282. doi:10.1016/S0885-3924(96)00149-2

28. Tengrup I, Tennvall-Nittby L, Christiansson I, Laurin M (2000) Arm morbidity after breast conserving therapy. Acta Oncol (Madr) 39:393-397. doi:10.1080/028418600750013177

29. Lugo M, Isturiz G, Lara C, Garcia N, Eblen-Zajjur (2002) Sensory lateralisation in pain subjective perception for noxious heat stimulus. Somatosens Mot Res 19(3):207-212. doi:10.1080/ 0899022021000009125

30. Riley JL, Robinson ME, Wise EA, Price DD (1999) A metaanalytic review of pain perception across the menstrual cycle. Pain 81:225-235. doi:10.1016/S0304-3959(98)00258-9
31. Neri M, Agazzani E (1984) Aging and right-left asymmetry in experimental pain measurement. Pain 19:43-48. doi:10.1016/ 0304-3959(84)90063-0

32. Schiff BB, Gagliese L (1994) The consequences of experimentally induced and chronic unilateral pain: reflections of hemispheric lateralisation of emotion. Cortex 30:255-267

33. Davidson RJ (1995) Brain asymmetry, emotion and affective style. In: Davidson RJ, Hugdahl K (eds) Brain asymmetry. MIT Press, Cambridge, pp 361-387

34. Coghill RC, McHaffie JG, Yen Y (2003) Neural correlates of interindividual differences in the subjective experience of pain. PNAS 100(14):8538-8542

35. Dar R, Ariely D, Frank H (1995) The effect of past injury on pain threshold and tolerance. Pain 60:189-193. doi:10.1016/03043959(94)00108-Q

36. Price DD, Milling LS, Kirsch I, Duffy A et al (1999) An analysis of factors that contribute to the magnitude of placebo analgesia in an experimental paradigm. Pain 83:402-411. doi:10.1016/ S0304-3959(99)00081-0

37. Tatrow K, Montgomery GH (2006) Cognitive behavioural therapy techniques for distress and pain in breast cancer patients: a meta-analysis. J Behav Med 29(1):17-27

38. Tracey I (2005) Nociceptive processing in human brain. Curr Opin Neurobiol 15:478-487. doi:10.1016/j.conb.2005.06.010

39. Han S, Song J, Yun Y, Yi S (2006) Effect of gamma radiation on cytokine expression and cytokine-receptor mediated STAT activation. Int J Radiat Biol 82(9):686-697. doi:10.1080/09553000 600930699

40. Galdiero M, Cipollaro del'Ero G, Folgore A, Cappelo M et al (1994) Effects of radiation doses on alterations in cytokine release by monocytes and lymphocytes. J Med 25:23-40

41. Spernal J, Krieg J, Lautenbacher S (2003) Pain thresholds as a putative functional test for cerebral laterality in major depressive disorder and panic disorder. Neuropsychobiology 48:146-151. doi:10.1159/000073632

42. McClure PW, Michener LA, Sennet B, Karduna AR (2001) Direct 3-dimensional measurement of scapular kinematics during dynamic movements in-vivo. J Shoulder Elbow Surg 10:269277. doi: $10.1067 / \mathrm{mse} .2001 .112954$

43. Ludewick PM, Cook TM (2000) Alterations in shoulder kinematics and associated muscle activity in people with symptoms of shoulder impingement. Phys Ther 80:276-291

44. Michener LA, McClure PW, Karduna AR (2003) Anatomical and biomechanical mechanisms of subacromial impingement syndrome. Clin Biomech (Bristol, Avon) 18:369-379. doi:10.1016/ S0268-0033(03)00047-0

45. Itoi E, Motzkin NE, Morrey BF, An KN (1992) Scapular inclination and inferior stability of the shoulder. J Shoulder Elbow Surg 1:131-139

46. Paletta GA, Warner JJ, Warren RF, Deutsch A, Altcheck DW (1997) Shoulder kinematics with 2 plane X-ray evaluation in patients with anterior instability or rotator cuff tearing. J Shoulder Elbow Surg 6:516-527. doi:10.1016/S1058-2746(97)90084-7

47. Fayad F, Roby-Brami A, Gautheron V, Lefevre-Colau M et al (2008) Relationship of glenohumeral elevation and 3-dimensional scapular kinematics with disability in patients with shoulder disorders. J Rehabil Med 40:456-460. doi:10.2340/165019770199 